\title{
Proposed Evaluation Criteria for Selecting Appropriate Cloud Based On-Demand CRM for SMEs.
}

\author{
Musarat Hasan Mujawar \\ Middlesex University. London, United Kingdom. \\ Capgemini Consulting, India. \\ musarat.hasanmujawar@gmail.com,musarat.mujawar@capgemini.com
}

\begin{abstract}
On-Demand CRM is of particular significance to small and medium-sized organizations as they are faced with budget and time restrictions. However, the failure rate of CRM in organizations is still considerably high. The CRM On-Demand market is saturated with multiple vendors offering similar solutions. Due to technological advancements, SME managers tend to not understand thoroughly the key drivers of On-Demand CRM solution. Some managers have left much of the understanding of the technical artifacts to the cloud vendors. There exists a research gap, which renders technical variables not part of the management decision-making activities. This research aims to address this gap in the CRM domain and focus on the technical aspects of evaluating On-Demand CRM in a bid to aid managers in decision-making. The design science research approach is adopted. Quantitative data analysis methods were used to test and validate the proposed evaluation criteria. The results indicate that from a technical quality perspective, there are various non-functional attributes that form a part of the CRM evaluation process in the cloud. This framework can be improved upon further by studying the functional, process and people factors that affect the buying decision of CRM.
\end{abstract}

Keywords-On-Demand; CRM; evaluation; cloud.

\section{INTRODUCTION}

CRM (Customer Relationship Management) is a technology-based and technology-integrated business process management strategy for applications marketing, sales and service that maximizes relationships between customer and organizations [4]. Cloud computing combined with OnDemand services over SAAS (Software-as-a-Service) architecture has penetrated CRM systems, too. Customers can access applications and data from a "cloud" anywhere in the world on-demand [1]. This has convinced many organizations to buy SAAS-based solutions irrespective of their geographic location. The On-Demand CRM market comprised 32\% in 2011 and $39 \%$ in 2012 of the total CRM market [2]. Hence, On-Demand CRM cloud-based SAAS applications for businesses are seen as a growing trend among organizations, especially SMEs (Small and Medium Enterprises). SMEs are defined as small and medium sized enterprises with a number of employees not greater than 250 and an annual turnover not greater than EUR 50 million [3]. Another point worth considering is that customer retention is also becoming increasingly important to SMEs because of their limited resources. Hence, SMEs, with their restricted budgets and deadlines look at cloud-based hosted CRM solutions as an attractive option. This is highly influenced by the pricing model of cloud-based SAAS CRM, which is valued on a per user per month basis [4]. The customer only has to pay for the usage of the service, which is much cheaper when compared to traditional On-Premise solutions, which entail high installation costs upfront [5]. However, for the sake of low costs and quick installation, the SME can be tricked into buying a solution that may not meet the business needs. This may result in loss of customers, which is unaffordable and a huge risk for the SME. Along with insufficient knowledge of On-Demand models of CRM and technological factors, AMR Research found that $47 \%$ of companies surveyed reported serious challenges with end user adoption [6].

The evaluation of On-Demand CRM selection is often confused with cloud service evaluation only, thereby neglecting other factors that can be CRM specific, as well as a mix of CRM and cloud technology. This requires managers to narrow their focus to On-Demand CRM systems within the cloud.

\section{RELATED CONCEPTS}

This section provides an overview of the concepts like cloud computing, cloud architecture and On-Demand CRM.

\section{A. On-Demand CRM}

On-Demand CRM is a low cost customer relationship management solution delivered over the Internet via the cloud. "Customer relationship management (CRM), is a model for managing a company's interactions with current and future customers, involves using technology to automate and 
synchronize sales, customer service and technical support" [8]. These are comparatively cheaper services compared to traditional On-Premise CRM solutions, as they do not require installation at the place of business. There is no maintenance or upgrade costs either, as the cloud provider of these services is responsible for maintaining these functions. The service is viewed as On-Demand, with customers paying only for what they use.

\section{B. Cloud Computing}

Cloud computing is considered a new technology trend as well as a disruptive technology ${ }^{1}$. There are many definitions for cloud computing. "Cloud Computing provides the facility to access shared resources and common infrastructure, offering services on-demand over the network to perform operations that meet changing business needs" [1]. Hence, customers will be able to access applications and data from a "cloud" anywhere in the world on-demand. It also provides facilities for users to manage their applications on the cloud, which entails the virtualization of resources [9]. However, these definitions are subjective and based on the perspectives they have been derived from. From the point of view of the users or consumers who actually use the services offered through the cloud, cloud computing could be defined in terms of the low cost, fast access, reliable form of service. From the point of view of vendors or suppliers, it is simply a model for providing and renting computer resources in a bid to optimize their use [10]. From a business point of view, it is a new way of reaching out to customers and providing services at a fast and reliable speed. Reference [11] describes SAAS as applications that are custom built as per business needs. They are provided to the end users via clouds that can be public, private or hybrid without the need to manage the platform on which they run or installing them on users' machines. An example of this is Salesforce.com CRM.

\section{Cloud CRM Architecture and SAAS}

SAAS is the basis of cloud CRM. The striking feature that makes it faster and more flexible when compared to OnPremise CRM is its multitenant architecture in a web-based framework. Multi-tenancy is an architecture framework in which a single instance of a software application serves many customers in isolated instances for each user. Each customer is called a 'tenant'. Tenants may be given the ability to customize some parts of the application, such as the page layout or the user interface, but they cannot change the application code. This is a kind of "one-to-many" model, whereby an application is shared across multiple clients. This framework promotes flexibility and greater speed, as there is no need to provide separate software for each tenant. They all have the same copy of the application, which they can access and customize, but each with a different user login. Hence, instead of installing and maintaining the software, users can access it

\footnotetext{
Technology or innovation that transforms business and global economy http://www.forbes.com/sites/gregsatell/2014/01/05/why-the-cloud-just-might-be-the-most-disruptivetechnology-ever/
}

via their internet browser, which frees the providers and businesses from complex and time-consuming software and hardware management. Thus, SAAS infrastructure and technology, alongside cloud computing, helps to improve the quality of CRM implementations and address CRM as a Service or "Hosted CRM".

\section{Scope And Limitations}

The project aims to narrow down the research in order to categorize cloud CRM specifically and specific end user usability attributes that influence the selection decision. The focus is limited to evaluating technological and end user attributes. The architectural factors are not considered extensively because there is already good research available on cloud applications evaluation frameworks, which is highly influenced by cloud architecture and deployment style [7]. In addition, vendor related financial factors were not considered within the scope of this research due to time limitations. As of now, no country limitations feature as part of this research. The remaining sections discuss the related concepts, literature review and research approach and results.

\section{RESEARCH APPROACH}

Design Science (DS) is a method via which the boundaries of human and organizational capabilities can be extended through the development of innovative artifacts [12]. This paper proposes evaluation criteria for selection of On-Demand CRM systems for SME. SME are goal oriented business entities. One problem in this area is the difference between the goal state and current state of the system. This problem is often solved by designing effective business processes [12]. Hence, a framework in the initial stage of the business process construction, such as pre-selection or selection of a CRM package, plays a major role in enabling effective business processes to achieve these goals. The real essence of the Design Science research method can be realized from the fact that it addresses two fundamental questions: 1) "What utility does the new artifact provide?" and 2) "What does that utility demonstrate?" In addition, the method also requires that the artifact or research adequately maps to the real world; in other words, this approach requires rigor. If it does not then there is no utility as it is not implementable. Thus, if there is no utility then its broad acceptance and future contribution is limited. The reasons highlighted above are the prime motivators for adopting this approach for research in the CRM domain regarding cloud-based software selection, as this research clearly addresses a real world problem and consider a tangible solution, or at least an implementable solution, which has been well evaluated as a part of the research. Reference [12] emphasizes on two very important stages of research. They are Develop/Build and Justify/Evaluate. A link is created between these two stages by focusing on the need to evaluate and justify the propositions so that they can be added to the existing knowledge base. The beauty of this approach is also understood from the fact that it challenges researchers to assess the relevance of the research topic they have chosen and its alignment with business needs within the organizational 
context. The methodology starts with a literature review to understand various parameters. A survey in the form of questionnaires is distributed to the CRM audiences including varied mix of respondents from all three perspectives i.e. Customer, provider and user. Quantitative analysis is conducted on the survey data collected. Correlation and Means method is adopted for analysis.

\section{LITERATURE REVIEW}

Reference [14] brings to light the strategic perspective that requires concerned stakeholders to take into account the cloud architecture and advancements while assessing the CRM solutions. Hence, any evaluation for On-Demand systems would lie at the intersection of cloud computing characteristics and CRM. Thus, the first task is to identify various stakeholders and their perspectives that will influence this decision. Reference [13] suggests there are two types of stakeholders in the area of CRM applications. One is the "consumers", which includes the companies that implement the CRM On-Demand solutions, IT investors and decision makers. Second is the "providers", which includes the vendors that provide the hosted On-Demand CRM solutions in the cloud-based architecture. However, another set of key stakeholder are "end users" of applications, who might be technical staff or non-technical teams such as sales or marketing. These users can no longer be termed as "web users". It may be more appropriate to call these CRM users "cloud users", considering the cloud infrastructure through which they access these applications. Thus, evaluation of OnDemand CRM needs to take into account these key sets of stakeholders and users and evaluate it from user perspective, too. Reference [15] propose the key quality factors, SAAS features and metrics for evaluating and assessing these quality attributes as based on IEEE 1061 standard which is the standard software quality evaluation methodology. The factors that they identified are reusability, customizability, data management, scalability, availability and pay per use. Thus, the attributes proposed can be seen as crucial from the cloud architecture point of view. Pay per use is a factor that is a significant economic consideration for a SME. Reference [15] work points out that in case of cloud-based SAAS applications; the software itself is a target of reuse. Reference [15] argues that reusability is no longer limited to the number of modules that can be re-used for different requirements. They associate scalability and availability to the properties of the process and network, rather than simply the system.

Reference [16] maintains that any CRM package is ultimately a software product and the product quality will highly influence any selection decision regarding the software. The product quality evaluation therefore forms an important part of any CRM evaluation. From an architectural point of view, reliability, control of data, integration, high availability and security parameters are of utmost importance to any cloud service evaluation. Although their work and framework can be generalized for any cloud application, some CRM specific evaluation attributes still need to be taken into consideration when making the selection decision. In the next section, we will consider cloud evaluation attributes in the context of OnDemand CRM.

Many authors suggest other non-technical attributes as being part of CRM evaluation. These are vendor market presence, TCO (total cost of ownership), pricing model or cost, vendors' roll-out time, service training and support, geographic reach and support, change management, management commitment, etc. [17][18][19][10][14]. As previously highlighted, these non-technical aspects have been thoroughly addressed in the literature. Reference [4] points out that the technology factor will be an enabler of entire business process and therefore needs to be constantly studied and addressed according to advancements in technology. Taking into consideration the scope of this research, we focus on the technical factors that affect the CRM On-Demand evaluation process. Vendor related attributes are not considered, as the expertise and dependability of vendors are context dependent and may vary according to geographic region and partner networks. The functional attributes of On-Demand CRM have been widely investigated in the literature and as such, all the functionalities present in On-Premise CRM are mirrored by vendors in On-Demand CRM. Reference [20] suggests that organizations must obtain an informed view of technology and perform technical evaluations to aid in a timely and balanced decision regarding CRM evaluation. The reason for emphasis on the technical variables is that many managers who are typically in-charge of the final selection of the CRM OnDemand application find it difficult to identify the technical variables. Reference [21] argues that organizations and managers have left much of the understanding of the technical IT artifacts to the technology vendors, for example cloud vendors. This view has been reinforced by the large number of whitepapers published by many cloud vendors discussing the technical details of the products and technology and their overall market implications [19][14][22]. However, it can be argued that viewing the assessment parameters through lens of the cloud CRM vendors may not always be the best decision, given the probability of vendors' biases and their intentions to market the product and technology they aim to sell.

Reference [21] points out that there does exist a research gap, particularly in the IS (Information Systems) field, which renders technical variables not part of management decisionmaking activities. We have therefore excluded the functional and other non-technical evaluation attributes related to process and people from the scope of this research.

\section{EVALUATION CRITERIA}

\section{A. Evaluation Attributes In Context Of On-Demand CRM}

1) Reliability: The degree to which a software product maintains a specified level of performance under specified conditions is referred to as its reliability [23]. In the context of On-Demand CRM, this reliability is the ability to ensure constant operation 
of the system without disruption, i.e., no loss of data, no code reset during execution, etc. It can be argued that there is a strong relationship between availability and reliability; however, reliability focuses in particular on the prevention of loss (of data or execution progress), which is vital in the case of CRM systems.

2) Availability \& Robustness: Availability is the ability of introducing redundancy for services and data so that failures can be transparently masked. With increasing concurrent access as a result of an increased number of CRM users logging in from a variety of devices such as mobile phones, web computers and tablets; availability is particularly achieved through replication of data/services and distributing them across different resources to achieve load-balancing.

3) Scalability: The ability of the On-Demand CRM application infrastructure to handle a growing number of resources accessing it is referred to as its scalability. On-Demand CRM is a cloud application and cloud systems focus largely on horizontal scalability (instance replication) rather than scalability (changes in the resource structure) [24].

4) Security, Privacy and Compliance: On-Demand CRM houses customer and critical business data. The security and privacy of data is observed as one of the top challenges of cloud CRM systems [25]. The most obvious concern is lack of control over data and code distribution. It can be argued that an attribute such as multi-tenancy, which is an important enabler of the provision of scalability, can also be seen as a disabler for security and privacy purposes. This is because multi-tenancy allows multiple users to access the same copy of an application in different instances. This could invite untrustworthy entities who may misuse the infrastructure for hacking and DOS (Denial of Service) attacks. In hosted CRM software, all data and applications are hosted in vendor servers in the cloud, and vendors are responsible for its security. Reference [25] argues that this might not go well with some organizations like financial banks and health enterprises, where confidentiality of data is a prime concern. Hence, such organizations may not opt to relinquish control of all their business data to external cloud providers. Mirrored data-centers, vendor backup and disaster recovery mechanisms in service level agreements (SLA), security audits and security attestation such as ISO27001 are seen as solutions for the security purposes by various groups. Jurisdiction of hosted data, legislation models in different countries and compliance of cloud providers with regulations in specific countries are also seen as issues (EU, 2010). The relative importance of this attribute cannot be side-lined, considering the nature of CRM business. Security and privacy concerns are seen as a never-ending issue in almost all web-based CRM applications. However, separate dedicated teams can be made available to address these issues.

5) Integration: In an InformationWeek research survey, Reference [26] argues that although integration facilities are provided by cloud CRM vendors, integration with non-SAAS applications remains a top SAAS challenge (62\%), as voted by 159 companies who use or are planning to use SAAS. CRM On-Demand is a SAAS product; hence, integration tools provided by cloud applications forms an important evaluation criteria for OnDemand CRM. This is because many CRM systems interact with legacy systems or pool data in and out from legacy systems.

6) Usability: Reference [23] defines Usability for software products as the capability of the software product to be understood, learned, used and be attractive to the user when used under specified conditions. Usability is an inherent and measurable property of all interactive digital technologies. The users are not simply the end users but also business users or non-technical users such as a sales team, marketing team, etc., for whom the ease of use of a system and its operability will enhance their time for marketing; thus, improving the efficiency of business processes.

7) Customization: It is defined as the ability to tailor the system according to business needs [23]. This can mean tailoring or customizing the business process functionality or the usability features. This is broadly referred to as configuration in within the context of CRM. Reference [22] argues that the customization ability of the On-Demand model is restricted to a codeless basis as a result of security reasons. Hence, one attribute may sometimes suffer at the cost of making others better. However, with the high level of complexity of business requirements observed in this agile work era, this attribute has gained due importance.

8) Mobility: Reference [19] defines mobility for CRM applications as the ability of the CRM solution to support a mobile workforce. This includes the breadth of platforms supported and online and offline capabilities according to the functionality addressed. Social media integration is another current market differentiator. Some features include mobile device application and support, iPad and tablet support, cross-browser CRM application support and social media integration (Facebook, Twitter, LinkedIn) with CRM applications. Real-time access to a CRM system through mobile phones (WAP, WML and voice), real-time access to CRM system through PDAs, Palm, Windows and BlackBerry devices etc., are vital for cloud-based CRM evaluation. Most 
CRM applications today cannot ignore this attribute, as it truly functions as a market differentiator.

9) Multi-tenancy: The framework acts as an evaluation criteria, as it is based on cloud architecture. In this way, the same resource is assigned to potentially multiple users at the same time in multiple isolated instances. Information is maintained in separate tables for each user at a database level. However, there are variants of this option available for cloud systems. Discussion of these variants is not within the scope of this research. These are also not applicable to CRM systems, as most instances of application of CRM in the cloud are SAAS based with the multitenant variation of web-based architecture applied. Hence, this attribute is part of cloud architecture evaluation. Since most vendors provide CRM applications with the same variant of multi-tenancy, we wish to skip this as an evaluation attribute for OnDemand CRM.

10) Multi-Channel Support: The solutions ability for supporting a diverse array of communication channels such as email, in person, telephone, web portal interactions and social media can be defined as multi-channel support for CRM. All channels must be tightly integrated with the CRM application so that agents can handle client tickets coming in from all channels (emails, chat, telephone, social networks and web) without switching to any third party applications, i.e., he/she should be able to chat, reply to emails, take/dial calls, etc., all within the same application. Through recent research, Reference [27] concludes that high-quality seamless customer experience is impacted strongly by mobile and online communication channels. However, they warn SMEs not to neglect offline features and to make sure online and offline features are well connected, as the experience of one channel directly influences the customer's willingness to engage via another channel.

11) Reusability: The ability of the software code to be reused to serve multiple applications and thereby eliminating reworking and redundancy is referred to as its reusability [23]. Reference [15] argues that in the case of On-Demand CRM, the entire SAAS solution can be viewed as a unit of reuse provisioning services to different companies using the same OnDemand application with customizations as required according to user needs. Hence, this evaluation attribute is not considered particularly important in the case of On-Demand CRM evaluation.

12) Data Management: As per cloud SAAS infrastructure for CRM applications, many users access the same copy of an application. Many users can customize, add or remove data according to their business needs. Sometimes, in order to achieve scaling, data is distributed flexibly across multiple data sources. At the same time, the system needs to be aware of data location. The size of data may change at any time with the help of scalability; hence, data management is a crucial evaluation attribute for almost all cloudbased applications. This can also overlap with the security and privacy attribute of evaluation. It is also a crucial concern in the 'age of Big Data'. This aspect is, however, now more important at the vendor side, as they might have different ways of managing data [24]. Hence, we classify this attribute as vendor dependent, too, though it is impacted by the cloud architecture.

13) Analytics: In this era of Big Data, the volume of data continues to grow on a daily basis. Data also continues to grow in CRM applications. This in turn gives even more importance to analysis tools. Data analysis can yield insight into businesses for enhancing their competitive advantage [19]. This can help non-technical teams such as sales and marketing teams to generate leads and opportunities more efficiently and drive them to completion. These analytic features are current needs and should be part of even basic editions of On-Demand CRM applications. These analytic tools can also be used to conduct historical and comparative trend analyses to gain insight into emerging opportunities and critical issues. Reference [28] claim that these analytic features can help turn information into insights and turn these insights into results. One example is Dashboards within which, users can access a deeper analysis and specific records for diagnosing issues. Predictive analysis and data mining processes embedded in analytics features can help organizations gain additional business intelligence. These features can turn simple and huge volumes of data into Smart Data that enhances CRM productivity.

14) Reporting Tools: Following analysis of the huge volume of data, the requirement is to make this data available in the form of reports for easy understanding and tracking. This involves features in CRM application that facilitate creation, modification of reports and exporting, formatting, filtering, sorting and applying logic to data contained within the reports.

\section{RELEVANT THEORIES}

This research is based on the DS research approach proposed by Reference [12], which provides guidelines for researching in the information systems field to devise innovative artifacts. Cloud-based On-Demand CRM is a new technology trend and can be considered an innovation in itself, due to SAAS delivery mode of service. Reference [29] proposed a theory of Information Systems called the Technology Acceptance Model (TAM), which posits that 
perceived usefulness ${ }^{2}$ and perceived ease of use of a system determines an individual's intention to use the system. Reference [29] argues that new technologies are complex to a set of users who are already used to a particular system and a way of doing tasks. This gives rise to an element of uncertainty in their minds, which has a direct impact on the rate adoption of these technologies. Cloud- based On-Demand $\mathrm{CRM}$ is identified as one of the disruptive technologies that have transformed the way of doing business [30]. We therefore logically conclude that the evaluation of On-Demand CRM should also focus on attributes that will enhance the perceived ease of use of the system, which in turn will enhance its usefulness and rate of adoption by SME users. This attribute is identified as usability.

In another theory called "Diffusion of Innovations", Reference [31] argues that innovation's ${ }^{3}$ relative advantage has a direct impact on the rate of adoption of new technologies and systems. In this case, SMEs can be considered the unit of adoption or organizations. Relative advantage can be described as the potential benefit gained by adopting the innovation as opposed to using an existing idea or system [31]. Customization, analytics features and multiple channels of accessibility can be seen as innovative attributes in OnDemand CRM. The relative advantage gained can be considered in terms of increased customer satisfaction, faster cycle times and increased ROI for SME. These innovation attributes directly enhance the rate of adoption of On-Demand CRM by SMEs. Taking into account reference [31] theory, it can be said that the evaluation of On-Demand CRM will have a direct effect on its rate of adoption in SMEs. This is because the main goal of SMEs looking for cloud-based CRM solutions is to make the best use of cloud-based CRM OnDemand systems in order to enhance their business productivity and profitability. Reference [31] points out that any innovation exhibits some characteristics, for example, compatibility, complexity, trialability and observability, and that these characteristics affects its rate of adoption by SMEs. We have already discussed the relative advantage characteristic separately, as it can be measured more in economic terms, as previously discussed. We therefore excluded it from the list of evaluation and discussed the rest of the characteristics. By applying reference [31] theory, we also propose another evaluation attribute, i.e., "Free Product Trials", which were offered by cloud CRM vendors to SMEs. However, we consider this attribute to be more vendorspecific.

\section{ANALYSIS AND RESULTS}

\section{A. Mean}

The means of the proposed evaluation criteria indicate the average of the importance on 1-5 Likert scale as seen by the respondents. The criteria sorted according to the means

\footnotetext{
2 The extent to which an individual perceives that using the 'object' will increase the performance of the individual [29].

3 An idea, practice or object that is perceived new by an individual or unit of adoption [31].
}

(importance) are shown in the table I below. According to the respondents, the most important criteria from an architectural perspective are availability, reliability and security as shown in table I below. The most important evaluation attributes from the technical quality perspective are observed as usability and mobility with means above 4.0. Looking at the means below, it can be inferred that none of the attributes proposed as a part of the evaluation framework were seen as unimportant by the respondents.

TABLE I. MEANS OF ON-DEMAND CRM EVALUATION ATTRIBUTES

\begin{tabular}{|c|c|c|}
\hline Evaluation Attribute & Mean & Importance \\
\hline Reliability & 4.23 & $\begin{array}{c}\text { Very } \\
\text { Important }\end{array}$ \\
\hline Availability & 4.07 & $\begin{array}{c}\text { Very } \\
\text { Important }\end{array}$ \\
\hline Scalability & 3.97 & Important \\
\hline Security & 4.27 & $\begin{array}{c}\text { Very } \\
\text { Important }\end{array}$ \\
\hline Usability & 4.47 & $\begin{array}{c}\text { Very } \\
\text { Important }\end{array}$ \\
\hline Integration & 4.00 & Important \\
\hline Customization & 4.00 & Important \\
\hline Mobility & 4.03 & $\begin{array}{c}\text { Very } \\
\text { Important }\end{array}$ \\
\hline Multi-Channel Support & 3.83 & Important \\
\hline Analytics & 4.00 & Important \\
\hline Reporting Tools & 3.97 & Important \\
\hline Free Product Trials & 4.19 & $\begin{array}{c}\text { Very } \\
\text { Important }\end{array}$ \\
\hline
\end{tabular}

\section{B. Correlation}

Pearson's correlation is used to explore the relationship and strength of the relationship between attributes. On careful interpretation of the quantitative statistical output, it can be said that there was no negative correlation observed among any variables indicating that none of the attributes reverse the importance of other attributes. Hence, all attributes are deemed appropriate for the evaluation of On-Demand CRM. The value of Pearson's correlation coefficient indicates the strength of the relationships. Reference [32] suggests that for careful understanding of the strength of the relationships, the guidelines that can be applied which group correlations strength as small ( $\mathrm{r}$-value $=0.10$ to 0.29 ), medium ( $\mathrm{r}$-value $=$ 0.30 to 0.49$)$ and strong (0.50 to 1.0$)$ [33]. The correlation results are shown in table II below. Strong positive and moderate positive correlations among the attributes are selectively shown below.

TABLE II. CORRELATION OUTPUTS FOR ON-DEMAND CRM EVALUATION ATTRIBUTES

\begin{tabular}{|l|l|l|}
\hline Attribute & $\begin{array}{l}\text { Pearson's } \\
\text { correlation(p) }\end{array}$ & Strength \\
\hline Availability & \\
\hline
\end{tabular}


ICIT 2015 The $7^{\text {th }}$ International Conference on Information Technology

doi:10.15849/icit.2015.0029 C ICIT 2015 (http://icit.zuj.edu.jo/ICIT15)

\begin{tabular}{|c|c|c|}
\hline Reliability & 0.730 & \multirow{4}{*}{ Strong Positive } \\
\hline Scalability & 0.686 & \\
\hline Security & 0.652 & \\
\hline Reporting tools & 0.652 & \\
\hline \multicolumn{3}{|l|}{ Reliability } \\
\hline Availability & 0.730 & \multirow{5}{*}{ Strong Positive } \\
\hline Scalability & 0.697 & \\
\hline Security & 0.737 & \\
\hline Analytics & 0.677 & \\
\hline Reporting Tools & 0.605 & \\
\hline \multicolumn{3}{|l|}{ Scalability } \\
\hline Availability & 0.686 & \multirow{3}{*}{ Strong Positive } \\
\hline Reliability & 0.697 & \\
\hline Security & 0.602 & \\
\hline \multicolumn{3}{|l|}{ Security } \\
\hline Availability & 0.652 & \multirow{4}{*}{ Strong Positive } \\
\hline Reliability & 0.737 & \\
\hline Scalability & 0.602 & \\
\hline Reporting Tools & 0.789 & \\
\hline \multicolumn{3}{|l|}{ Integration } \\
\hline Customization & 0.429 & \multirow{2}{*}{ Moderate Positive } \\
\hline Mobility & 0.384 & \\
\hline \multicolumn{3}{|l|}{ Customization } \\
\hline Mobility & 0.627 & \multirow[b]{2}{*}{ Strong Positive } \\
\hline $\begin{array}{l}\text { Multi-Channel } \\
\text { Support }\end{array}$ & 0.632 & \\
\hline \multicolumn{3}{|l|}{ Usability } \\
\hline $\begin{array}{l}\text { Multi-Channel } \\
\text { Support }\end{array}$ & 0.646 & \multirow[t]{2}{*}{ Strong Positive } \\
\hline Analytics & 0.612 & \\
\hline \multicolumn{3}{|l|}{ Mobility } \\
\hline Customization & 0.627 & \multirow[b]{2}{*}{ Strong Positive } \\
\hline $\begin{array}{l}\text { Multi-Channel } \\
\text { Support }\end{array}$ & 0.760 & \\
\hline \multicolumn{3}{|c|}{ Multi-Channel Support } \\
\hline Customization & 0.632 & \multirow{2}{*}{ Strong Positive } \\
\hline Usability & 0.646 & \\
\hline \multicolumn{3}{|l|}{ Analytics } \\
\hline Reporting Tools & 0.811 & \multirow{2}{*}{ Strong Positive } \\
\hline Usability & 0.612 & \\
\hline \multicolumn{3}{|l|}{ Reporting Tools } \\
\hline Security & 0.789 & \multirow{2}{*}{ Strong Positive } \\
\hline Analytics & 0.811 & \\
\hline \multicolumn{3}{|c|}{ Free Product Trials } \\
\hline Availability & 0.399 & \multirow{3}{*}{ Moderate Positive } \\
\hline Reliability & 0.577 & \\
\hline Usability & 0.595 & \\
\hline
\end{tabular}

identifying and proposing evaluation criteria for cloud CRM for SMEs from a technical quality and user perspective. The two attributes with strongest positive correlations between them were reporting tools and analytics. These attributes are utmost important in this era of Big Data as the businesses in order to enhance their competitive advantage need to capture markets through good analysis of huge data at their disposal [19]. However, in order to gain proper insights from these data and turn them into results and prospective business opportunities, a good reporting feature is inevitable. This is because managers who analyze and transform this data into results need a user friendly interface to transform and understand the data. This all has to be well integrated in the same system. Many participants suggested Free product trials as an evaluation attribute. This was observed as an attractive feature that lets SMEs test and experience the CRM cloud system and its capabilities well before buying them and perform a suitability check. However, in cases where it doesn't fit the company's needs, customization abilities can be considered as a deciding feature. This is illustrated by the fact that customization to suit client needs was considered as an important attribute by all organizations in the survey irrespective of the size of the organizations. The research findings add to a growing body of literature on cloud-based On-Demand CRM and evaluation. This meets one of the guidelines of the Design Science research approach that requires the research conducted should make a good contribution to the existing knowledge base [12].

\section{CONCLUSION}

In this paper, we proposed On-Demand CRM evaluation criteria from a technology and end-user perspective. This can ultimately enable decision makers to make a sound choice of a cloud-based On-Demand CRM solution for their business needs. The initial literature review helped us extract appropriate On-Demand SAAS based CRM evaluation attributes and cloud evaluation attributes. These were then filtered as per the scope of the research. Evaluation criteria was tested, validated and evaluated through a survey and quantitative analysis.

\section{FUTURE WORK}

In future, the participants could be interviewed as well as surveyed using a mixed method approach to gain a deeper understanding of the subject. This study can be extended to focus only on large organizations and the results can be compared with the results of the SMEs to gain a better understanding of the evaluation criteria for cloud CRM. In addition to this, the research could also be conducted across the organizations in a specific country. As highlighted earlier, the people and process factors were not considered within the scope of this research. However, CRM as a business strategy is a mix of three factors: people, process and technology. The incorporation of the proposed evaluation criteria with the people and process factors such as functionalities offered by CRM system, cost etc. can provide a more complete and robust framework for evaluation. 


\section{ACKNOWLEDGMENT}

The author is grateful to the respondents and experts who aided in carrying out research for this work. The author expresses sincere gratitude to Dr. Barnaby Martin and Middlesex School of Science \& Technology for their support and guidance.

\section{REFERENCES}

[1] Kulkarni, G., Gambhir, J. \& Palwe, R., "Cloud Computing-Software as Service," International Journal of Cloud Computing and Services Science (IJ-CLOSER),vol. 1, no. 1, pp. 11 - 16, 2012.

[2] Gartner. "Predicts 2013: CRM Goes More Cloud, Becomes an App, Has a New Leader and Changes Name", available online at: https://www.gartner.com/doc/2264615/predicts--crm-goes-cloud.

[3] EU Commission."EU Enterprise and Industry: What is an SME? ", available online at: http://ec.europa.eu/enterprise/policies/sme/factsfigures-analysis/sme-definition/ .2003.

[4] Chen, I. \& Popovich, K., "Understanding customer relationship management (CRM) People, process and technology", Business Process Management Journal, vol.9, no. 5, pp. 672-688, 2003.

[5] Overby, S.,"The Truth About On-Demand CRM", CIO Magazine, 2006.

[6] CRM Landmark, "How big is the CRM software-as-a-service industry? How fast will it grow? When will it cap? ", available online at: www.crmlandmark.com/saasmarket.htm, 2013.

[7] Reixa, M., Costa, C. and Manuela, A, "Cloud services evaluation framework", In Proceedings of the Workshop on Open Source and Design of Communication, ACM, pp. 61-69, 2012.

[8] R.Shaw, "Computer Aided Marketing \& Selling", ButterworthHeinemann, Oxford, 1991

[9] Gajala, C, "Cloud Computing: A State of Art of the Cloud",International Journal of Computer Trends and Technology, vol. 4, no.1, pp. 35-38, 2013

[10] Miguel, R., Carlos, C. \& Manuela, A, "Cloud Services Evaluation Framework", In Proceedings of the Workshop on Open Source and Design of Communication, pp.61-69, 2012.

[11] Hoefer, C. N. \& Karagiannis, G,"Taxonomy of cloud computing services", GLOBECOM Workshops (GC Wkshps), IEEE, pp.13451350,2010

[12] Hevner, A. R., Jinsoo, P., March, T. S. \& Ram, S., "Design Science in Information Systems Research". MIS Quarterly, vol. 28, no.1, pp. 75105, 2004.

[13] Thanawin, R. \& Veeragandham, M., "CRM: Software as a Service versus On-premise-benefits and drawbacks", 2009.

[14] Saugatuck Technology, "Toward a Framework for Evaluating Cloudbased CRM", 2011.

[15] Lee, J. Y., Lee, J. W., Cheun, D. W. \& Kim, S. D.,"A Quality Model for Evaluating Software-as-a-Service", IEEE Computer Society, pp. 263266, Washington, DC, 2009.

[16] Colombo, E. \& Francalanci, C., "Selecting CRM packages based on architectural, functional, and cost requirements: Empirical validation of a hierarchical ranking model", Requir. Eng., vol. 9, no. 3, pp. 186-203, 2004

[17] Almotairi, M., "CRM Success Factors Taxonomy", European and Mediterranean Conference on Information Systems(EMCIS2008), pp.29-35, 2008.

[18] Eid, R, "Towards a Successful CRM Implementation in Banks: An Integrated Model", The Service Industries Journal, vol. 27, no.8, pp. 1021-1039, 2007.

[19] Ovum,"Ovum Decision Matrix: Selecting a CRM Vendor in the Life Sciences Industry", 2012.

[20] Brown, A. W. \& Wallnau, K. C., "A Framework for Systematic Evaluation of Software Technologies", IEEE Software, vol. 13, no.5, pp.39-49, 1996
[21] Orlikowski, W. J. \& Iacono, S. C., "Research Commentary: Desperately Seeking the "IT" in IT Research- A call to theorizing the IT Artifact", Information Systems Research, vol. 12, no. 2, pp. 121-134, 2001

[22] Sage CRM, "On-demand or on-premise CRM: 5 things to consider before making your decision", available online at: https://community.sagecrm.com/user_community/m/whitepapers/3473.a spx, 2010.

[23] Khosravi, K. \& Gueheneuc , Y.G., "A Quality Model for Design Patterns", German Industry Standard, 2004.

[24] EU, E. C., "The Future of Cloud Computing", 2010.

[25] Pombriant, D. \& Greenberg, P., "The top on-demand CRM and SaaS CRM FAQs", available online at: http://searchcrm.techtarget.com/feature/The-top-on-demand-CRM-andSaaS-CRM-FAQs, 2009.

[26] Weier, H., "SaaS Integration: Real-World Problems, And How CIOs Are Solving Them", available online at: http://www.informationweek.co.uk/services/saas/saas-integration-realworld-problems-and/211200952, 2008.

[27] IBM, "Delivering a seamless experience across every channel", New York: Econsultancy, 2013.

[28] IBM, "Business analytics in the cloud", IBM Industries, New York, 2012.

[29] Davis, F. D., "Perceived Usefulness, Perceived Ease of Use, and User Acceptance of Information Technology", MIS Quarterly, vol. 13, no. 3, pp. 319-340, 1989.

[30] Infosys, "Cloud Computing", vol. 7, no. 7, 2009.

[31] Rogers, E. M., "Diffusion of innovations", 5th ed., Free Press, New York, 2003

[32] Pallant, J., "SPSS Survival Manual, A step by step guide to data analysis using IBM SPSS", 5th ed., Maidenhead: Open University Press, 2013.

[33] Cohen J., "Statistical Power analysis for the behavioural sciences", 2nd ed., Lawrence Erlbaum associates, New York, 1988. 